\title{
Modelling of cryogenic processes in permafrost and seasonally frozen soils
}

\author{
H. R. THOMAS*, P. CLEALL*, Y.-C. LI* ${ }^{*}$ C. HARRIS $\dagger$ and M. KERN-LUETSCHG $\dagger$
}

This paper investigates the thermo-hydro-mechanical (THM) behaviour of soils subjected to seasonal temperature variations in both permafrost and seasonally frozen conditions. Numerical modelling of soil freezing and ice segregation processes is presented, and compared against small-scale physical modelling experiments. The coupled THM model presented, which is solved by way of a transient finite element approach, considers a number of processes, including conduction, convection, phase change, the movement of moisture due to cryogenic suctions, and the development of ice lenses. Two seasonal freezing scenarios are considered: (a) for soils with no permafrost, where freezing is from the surface downward (one-sided freezing); and (b) for soils underlain by permafrost, where large thermal gradients in the uppermost permafrost layer can cause active layer freezing in two directions, from the permafrost table upwards and from the ground surface downwards (two-sided freezing). In the case of one-sided freezing, ice lens formation occurs as the freezing front advances downwards from the surface, and is limited by water supply. However, during two-sided freezing, ice segregation takes place in a closed system, with ice lenses accumulating at the base of the active layer and near the ground surface, leaving an intervening ice-poor zone. Numerical modelling is able to represent the development of both the thermal field and ice segregation observed in the physical models. The significance of this contrasting ground ice distribution is considered in the context of thaw-related slow mass movement processes (solifluction).

KEYWORDS: deformation; ground freezing; numerical modelling; temperature effects
La présente communication se penche sur le comportement thermo-hydro-mécanique (THM) de sols soumis à des fluctuations saisonnières de la température dans le pergélisol et le gel saisonnier. Elle présente également une modélisation numérique des procédés de congélation du sol et de ségrégation de la glace, et en effectue la comparaison avec des expériences de modélisation physique à petite échelle. Le modèle à THM couplé ainsi présenté, résolu par le biais d'une méthode aux éléments finis transitoires, examine un certain nombre de procédés, y compris la conduction, la convection, le changement de phase, les déplacements de l'humidité sous l'effet d'aspirations cryogéniques, et le développement de lentilles de glace. Deux scénarios de congélation saisonnière sont examinés : (i) pour les sols sans pergélisol, c'est à dire dans lesquels le gel évolue de la surface vers le bas (gel unidirectionnel), et (ii) pour les sols à pergélisol sousjacent, dans lesquels d'importants gradients thermiques dans la couche supérieure du pergélisol peuvent donner lieu à une congélation de la couche active dans les deux sens, c'est à dire de la couche de pergélisol vers le haut, et de la surface vers le bas (gel bidirectionnel). Dans le cas du gel unidirectionnel, une formation de lentilles de glace se produit au fur et à mesure de la progression vers le bas du front de congélation, limitée par la fourniture d'eau. Toutefois, dans le gel bidirectionnel, la ségrégation de la glace se déroule dans un système fermé, des lentilles de glace s'accumulant à la base de la couche active, et à proximité de la surface, en laissant une zone intercalée pauvre en glace. La modélisation numérique permet de représenter le développement du champ thermique et de la ségrégation de la glace observée dans les modèles physiques. On examine l'importance de cette distribution contrastée de la glace au sol dans le contexte des procédés à mouvements de masse lents relatifs au dégel (solifluction).

\section{INTRODUCTION}

In cold regions, the soil near the ground surface may freeze in response to seasonal temperature variations. The soilfreezing process is often accompanied by frost heave and ice segregation. Frost heave and ice segregation can potentially cause many engineering problems, including cracking of pavements, damage to the foundations of structures, and fracture of pipelines. An additional problem that is often linked to seasonal ice segregation is that of periglacial solifluction on slopes (Harris, 1996; Matsuoka, 2001; Harris et al., 2007) during the thaw phase of the freeze-thaw cycle.

Manuscript received 2 May 2008; revised manuscript accepted 19 December 2008.

Discussion on this paper closes on 1 September 2009, for further details see p. ii.

* Geoenvironmental Research Centre, Cardiff School of Engineering, Cardiff University, Wales, UK.

$\dagger$ School of Earth Sciences, Cardiff University, Wales, UK.
A number of experimental investigations have reported the response of frost-susceptible soils to various freezing and thawing regimes at various scales (Penner, 1986; Harris, 1996; Matsuoka, 2001; Harris et al., 2007). Such investigations span from small-scale column-freezing tests (Penner, 1986), to scale centrifuge tests (Harris, 1996; Kern-Luetschg et al., 2008), through large-scale tests (Harris et al., 2008b) to long-term field-scale monitoring (Harris, 1996; Harris et al., 2007). It has been found that the type of boundary conditions present impact greatly on the styles of freezing and subsequent ground movements. However, a good correlation between the various scales has been found (Harris et al., 2008b). In the context of solifluction processes, a strong correlation between the downslope movements and the location of ice-rich soil layers has been observed (Harris et al., 2008a), and therefore it is of value if the location of such layers, where ice lensing has occurred, can be identified. This paper reports on the development of a numerical model to simulate the possible location of such lenses, and thereby contribute towards the development of models to predict the 
style and quality of downslope movements exhibited by a frozen slope on thawing.

A number of studies have investigated the development of models to predict frost heave that include the consideration of ice segregation. Gilpin (1980) developed a model to predict ice lensing and heave rates as a function of basic soil properties: the model assumed that all of the latent heat release occurs either at the isotherm or the temperature at which an ice lens is growing, and that thermal conductivities in each zone (that is, frozen zone, frozen fringe and unfrozen zone) are constant. Konrad \& Morgenstern (1980) presented a theory of frost heave based on segregation potential and ice lens formation in fine-grained soils, and used a segregation-freezing temperature, which is sensitive to overburden load, to decide ice lens formation. Nixon (1991) summarised limitations or shortcomings of this theory, including that it does not explicitly predict the key parameter in terms of more fundamental soil parameters, and it assumes that the overburden pressure and suction at the frost front affect the heave rate independently. O'Neill \& Miller (1985) presented a rigid ice model of frost heave assuming pore ice motion by regelation, which while lacking experimental validation was found to correlate well with the measured observations. Nixon (1991) extended the Gilpin (1980) model and accounted for the effects of distributed phase change within the frozen fringe in both the heat and mass transfer components of the formulation. However, this model assumes that all in-situ pore water phase change takes place at the freezing point, and that the temperature profile remains linear in the frozen fringe. Moreover, this model assumes no pore water phase expansion, and a constant pore water velocity through the frozen fringe. Konrad \& Duquennoi (1993) proposed a model for water transport and ice lensing in incompressible saturated soils based on the thermodynamic equilibrium of open system freezing and a failure strain criterion for initiating a new ice lens. Although of interest, the model requires some input values, such as the efficiency of the freezing system and the fraction of energy for heat engines, that are difficult to establish.

It is well known that the soil-freezing process involves coupled heat transfer, moisture transfer and force equilibrium, accompanied by pore water phase change. However, all the models above assume that the freezing soil is incompressible, and include only heat and mass transport in the soil-freezing process. Therefore any consolidation that may occur as a result of pore water transfer cannot be taken into consideration. For consideration of stability problems in cold regions, such as periglacial solifluction, a coupled flow and stress-strain analysis offers an improved insight into the system's behaviour. In addition, almost all of the work is focused on the one-sided freezing mode, which usually occurs in the seasonally frozen regions without permafrost, with limited effort focused on the two-sided freezing mode, which occurs in the permafrost regions. Field measurements and laboratory simulations show that one-sided and twosided freezing modes may form different distributions of segregation ice, which results in varied styles of periglacial solifluction for seasonally frozen and permafrost regions (Matsuoka, 2001).

In this paper, a coupled thermo-hydro-mechanical model, including ice segregation, is presented to simulate the soilfreezing process. Stress-strain equilibrium is incorporated with heat and mass transport, and a stress criterion for initiating new ice lensing is adopted. The highly non-linear governing differential equations are solved by a Galerkinweighted residual technique in the space domain and an implicit integrating scheme in the time domain. This model is then applied to consider two typical seasonal freezing scenarios, namely in regions without permafrost (one-sided freezing) and regions with permafrost (two-sided freezing). Results of the numerical modelling are then compared with observed behaviour in a series of physical models. Finally the significance of this contrasting ground ice distribution is considered in the context of thaw-related slow mass movement processes (solifluction).

\section{THEORY}

The soil is assumed to be a saturated, isotropic and elastic medium within which the soil is fully frozen, partially frozen or unfrozen. The frozen soil consists of solid grains, pore ice and ice lenses. The partially frozen soil is considered to consist of solid grains, pore ice and pore water. The unfrozen soil consists only of soil grains and pore water. The solid grains, pore water and ice are assumed as being incompressible under the pressure and temperature conditions existing in cold regions. Local thermal equilibrium is assumed, that is, the local temperature is the same for soil solid, pore water and ice. The freezing point of water is assumed constant, and its depression under loading is negligible. The main thermo-hydraulic-mechanical interactions considered are illustrated in Fig. 1.

\section{Processes of soil freezing, including ice segregation}

As the surface temperature of a soil sample drops below the freezing point, the freezing front penetrates the sample progressively, as shown in Fig. 2. Unsteady heat flow due to the thermal gradient with depth leads to a decrease of the soil temperature. Phase change of pore water occurs in the so-called 'frozen fringe' (Miller, 1972), when the soil temperature falls below the freezing point; also, at this point latent heat of fusion is released. Volumetric expansion of water due to phase change (liquid to ice) causes an increment of pore pressure within the unfrozen pores. At the ice/ water interface a cryogenic suction gradient, which is developed in response to the temperature gradient, draws the pore water in the unfrozen soil towards the freezing front, which in turn raises pore pressure there. The thermally induced driving force causing pore water flow by the temperature gradient can be determined using the Clapeyron equation, whereby consideration of the thermodynamics of the system

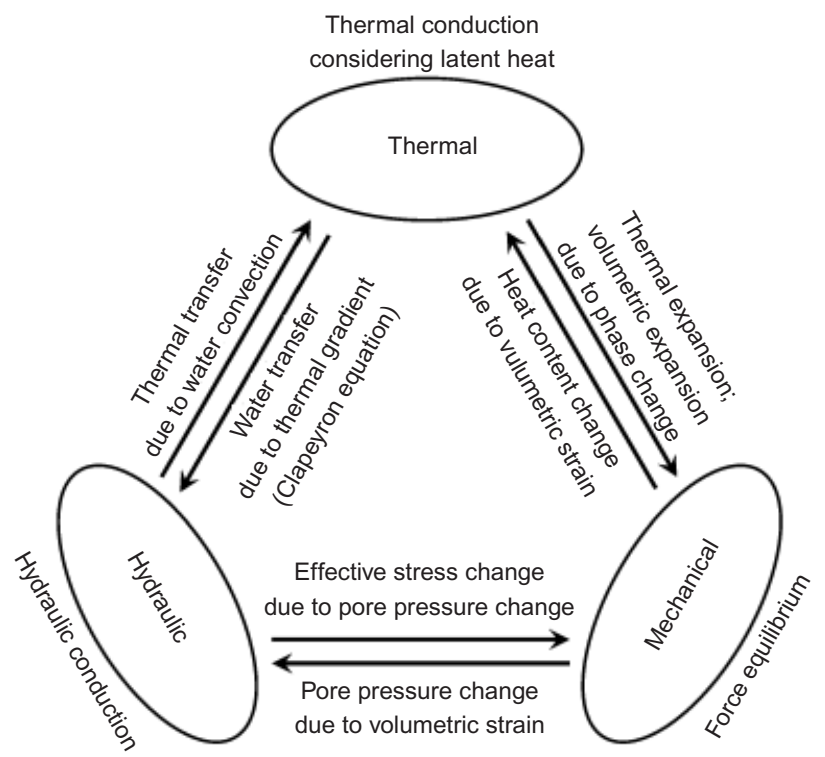

Fig. 1. Thermo-hydro-mechanical interaction mechanism in freezing soils 


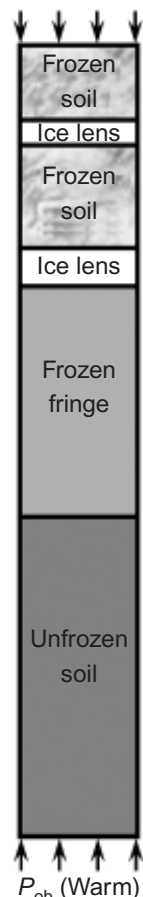

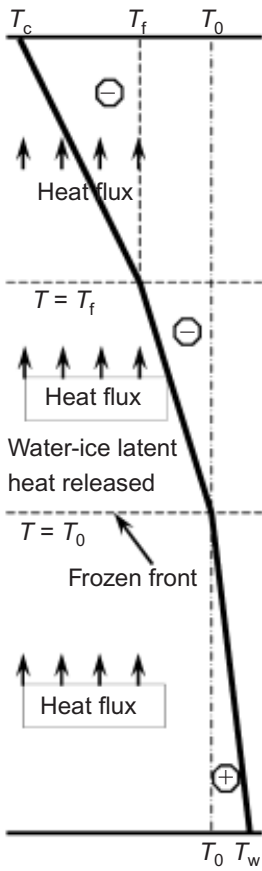

(a)

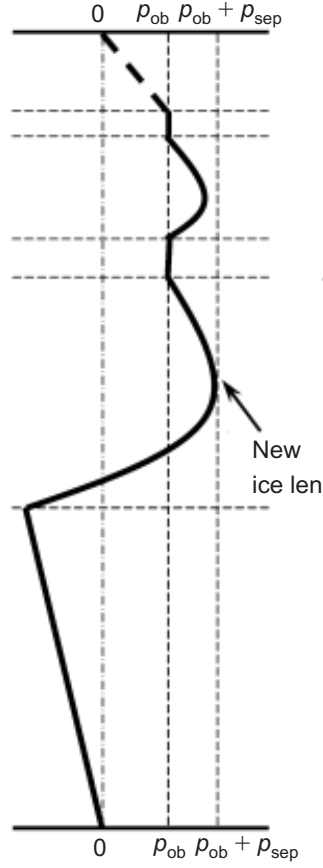

(b)

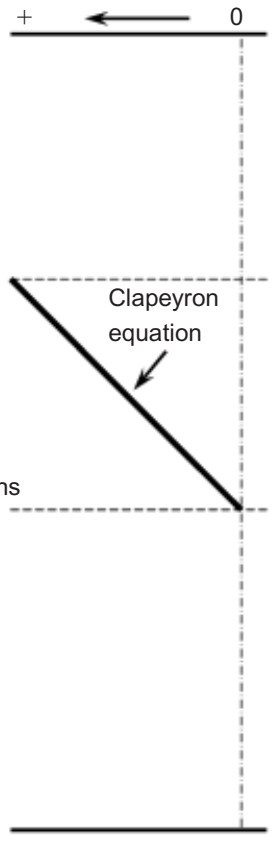

(c)

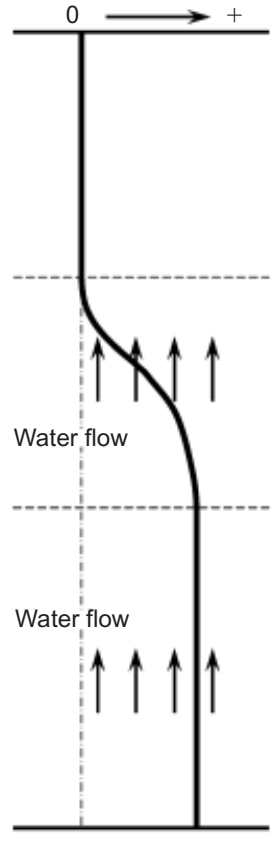

(d)

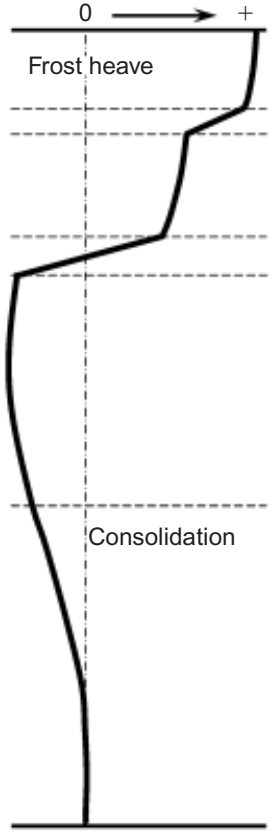

(e)

Fig. 2. Schematic representation of a freezing soil with ice segregation: (a) layers; (b) temperature; (c) pore pressure; (d) cryogenic suction; (e) water velocity; (f) displacement $\left(T_{\mathrm{c}}, T_{\mathrm{w}}\right.$, temperature at cold and warm ends, respectively; $T_{\mathrm{f}}$, temperature at the base of ice lens; $T_{0}$, freezing point; $p_{0 \mathrm{~b}}$, surface overburden load; $p_{\text {sep }}$, separation strength)

shows that the chemical equilibrium for the chemical potentials of ice and water is satisfied (Black, 1995; Henry, 2000). Ice segregation takes place if the pore pressure reaches a threshold value, and a new ice lens forms in the direction of heat removal (Miller, 1978; Gilpin, 1980; O’Neill \& Miller, 1985; Nixon, 1991). Moisture accumulation and the volumetric expansion due to pore water phase change in both the fully frozen soils and ice lens result in frost heave.

\section{Moisture transfer}

The volumetric moisture content for freezing soils is defined as the sum of the volumetric water content $\theta_{1}$ and the volumetric ice content $\theta_{\mathrm{i}}$ respectively, which are defined as $\theta_{1}=n\left(1-S_{\mathrm{i}}\right)$ and $\theta_{\mathrm{i}}=n S_{\mathrm{i}}$. Here $n$ is the porosity of the freezing soil; $S_{\mathrm{i}}$ refers to the degree of moisture with respect to ice, and can be represented by a power function of the temperature according to many experiments with varying water contents and different physical properties (Tice et al., 1976), as

$$
S_{\mathrm{i}}=1-\left[1-\left(T-T_{0}\right)\right]^{\alpha}
$$

where $T$ is temperature and $T_{0}$ is the freezing point of pore water (both in Kelvin), and $\alpha$ is a parameter that is dependent on pore size if variations of the chemical composition of the pore liquid are not considered. As this relationship only tends towards unity a threshold value of $S_{\mathrm{i}}$ is used to indicate a fully frozen state within the model. Fig. 3 shows the relationship of $S_{\mathrm{i}}$ and $T$ with $\alpha$ ranging from -10 to -1 .

The law of mass conservation of the moisture for freezing soils can be expressed as

$$
\frac{\partial\left(\rho_{1} \theta_{1} \mathrm{~d} V\right)}{\partial t}+\frac{\partial\left(\rho_{\mathrm{i}} \theta_{\mathrm{i}} \mathrm{d} V\right)}{\partial t}+\rho_{1} \nabla \boldsymbol{v}_{\mathrm{l}} \mathrm{d} V+\rho_{\mathrm{i}} \nabla \boldsymbol{v}_{\mathrm{i}} \mathrm{d} V=0
$$

where the subscripts 1 and $\mathrm{i}$ refer to pore water and ice

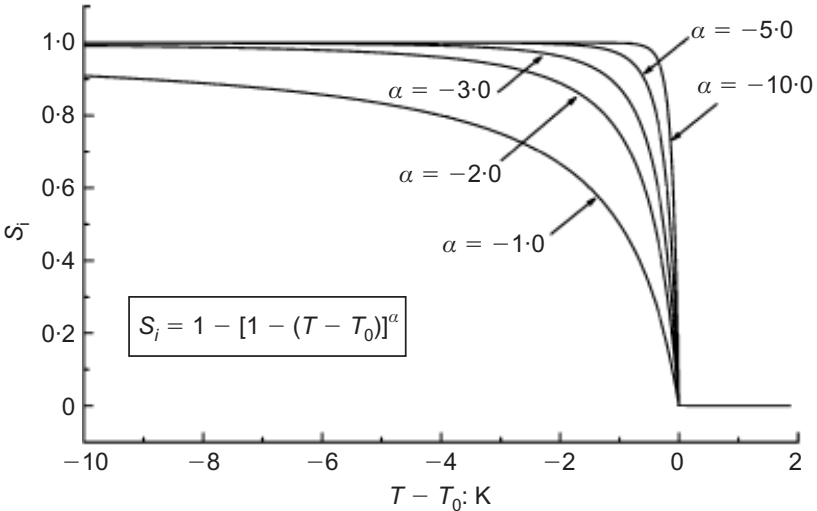

Fig. 3. Model of the relationship between degree of moisture respect to ice and temperature

respectively; $\rho$ is the density; $\boldsymbol{v}$ is the velocity relative to the solid skeleton; $\mathrm{d} V$ refers to the volume element of the soil; and $t$ is the time. Darcy's law is adopted to describe the pore water flow in terms of the piezometric head $\phi_{1}=u_{1} / \gamma_{1}+z$ (Bear \& Verruijt, 1987) as

$$
v_{1}=-k_{1} \nabla \phi_{1}=-\frac{k_{1}}{\gamma_{1}} \nabla\left(u_{1}+\gamma_{1} z\right)
$$

where $\gamma_{1}$ is the unit weight of water; $u_{1}$ is the pore water pressure; $z$ is the elevation; and $k_{1}$ is the hydraulic conductivity, which is assumed to be a function of the temperature in the form (Gilpin, 1980; Nixon, 1991)

$$
\frac{k_{1}}{k_{10}}=\left[1-\left(T-T_{0}\right)\right]^{\beta}
$$

where $k_{10}$ is the hydraulic conductivity when the soil is fully unfrozen, and $\beta$ is a soil parameter that is dependent on pore 
size and structure. Fig. 4 shows the relationship of $k_{1} / k_{10}$ and $T$ with different $\beta$ ranging from -8 to -40 .

For freezing soils, numerous experiments have shown that the thermal gradient causes the movement of pore water in the direction of lower temperatures under uniform pressure fields (Hoekstra, 1966; Mageau \& Morgenstern, 1980). The thermally induced driving force causing pore water flow by the temperature gradient can be determined using the Clapeyron equation on the basis of thermodynamics (Black, 1995; Henry, 2000),

$$
\frac{u_{1}}{\rho_{1}}-\frac{u_{\mathrm{i}}}{\rho_{\mathrm{i}}}=L \operatorname{In} \frac{T}{T_{0}}
$$

where $u_{\mathrm{i}}$ is the ice pressure and $L$ is the latent heat of fusion. The cryogenic suction due to the ice/water interface tension, $S_{\mathrm{T}}$, is

$$
\begin{aligned}
S_{\mathrm{T}} & =u_{1}-u_{\mathrm{i}} \\
& =u_{1}-\rho_{\mathrm{i}}\left(\frac{u_{1}}{\rho_{1}}-L \operatorname{In} \frac{T}{T_{0}}\right) \\
& \approx \rho_{1} L \operatorname{In} \frac{T}{T_{0}} \\
& \approx \rho_{1} L \frac{T-T_{0}}{T_{0}}
\end{aligned}
$$

Assuming the pressure and temperature to be independent driving forces for the pore water flow, equation (3) can be modified following the approach taken by Nakano (1990) as

$$
\begin{aligned}
\boldsymbol{v}_{l} & =-\frac{k_{1}}{\gamma_{1}} \nabla\left(u_{1}+\gamma_{1} z+S_{\mathrm{T}}\right) \\
& =-\frac{k_{1}}{\gamma_{1}}\left[\nabla\left(u_{1}+z \gamma_{1}\right)+\frac{\rho_{1} L}{T_{0}} \nabla T\right]
\end{aligned}
$$

The velocity of pore ice relative to the solid skeleton is ignored, so $v_{\mathrm{i}}=0$. The volume element of the soil $\mathrm{d} V$ can be expressed with respect to the solid volume of the soil $\mathrm{d} V_{\mathrm{s}}$ as $\mathrm{d} V=(1+e) \mathrm{d} V_{\mathrm{s}}$. The porosity of the soil can be expressed in terms of the void ratio $e$ as $n=e /(1+e)$. Then equation (2) can be expanded to yield

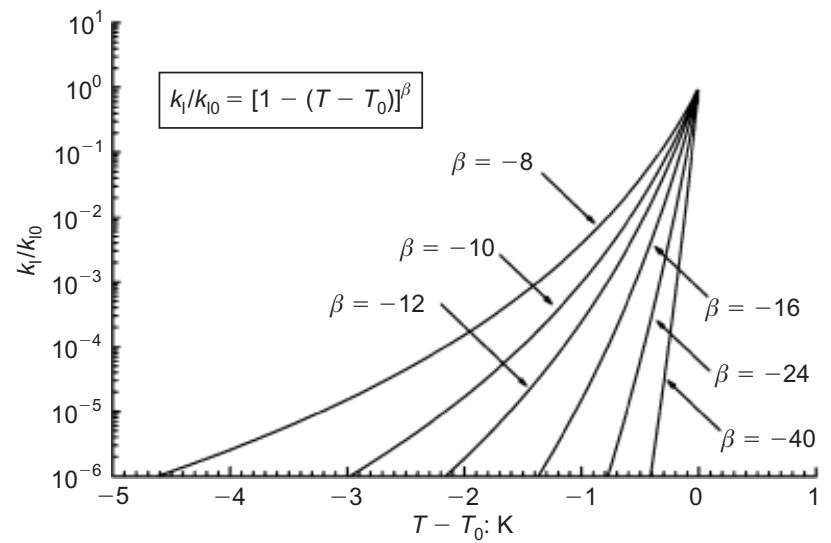

Fig. 4. Model of the relationship between hydraulic conductivity and temperature

$$
\begin{aligned}
& \rho_{1}\left[\frac{1}{1+e} \frac{\partial e}{\partial t}\left(1-S_{\mathrm{i}}\right)-\frac{\partial S_{\mathrm{i}}}{\partial t} \frac{e}{1+e}\right] \\
& \quad+\rho_{\mathrm{i}}\left(\frac{1}{1+e} \frac{\partial e}{\partial t} S_{\mathrm{i}}+\frac{\partial S_{\mathrm{i}}}{\partial t} \frac{e}{1+e}\right) \\
& \quad-\rho_{1}\left[\nabla\left(\frac{k_{1}}{\gamma_{1}} \nabla u_{1}\right)+\nabla\left(\frac{k_{1}}{\gamma_{1}} \frac{\rho_{1} L}{T_{0}} \nabla T\right)+\nabla\left(k_{1} \nabla z\right)\right]=0
\end{aligned}
$$

Here

$$
\frac{1}{1+e} \frac{\partial e}{\partial t}=\frac{\partial \varepsilon_{\mathrm{v}}}{\partial t}=\boldsymbol{m}^{\mathrm{T}} \frac{\partial \boldsymbol{\varepsilon}}{\partial t}=\boldsymbol{m}^{\mathrm{T}} \boldsymbol{P} \frac{\partial \boldsymbol{u}}{\partial t}
$$

where $\varepsilon_{\mathrm{V}}$ refers to the volumetric strain. For two-dimensional problems, the differential operator $\boldsymbol{m}^{\mathrm{T}}=[1,1,0]$, the strain vector $\boldsymbol{\varepsilon}=\left[\varepsilon_{x}, \varepsilon_{z}, \gamma_{x z}\right]^{\mathrm{T}}$, the strain matrix

$$
\boldsymbol{P}=\left[\begin{array}{ccc}
\frac{\partial}{\partial x} & 0 & \frac{\partial}{\partial z} \\
0 & \frac{\partial}{\partial z} & \frac{\partial}{\partial x}
\end{array}\right]^{\mathrm{T}}
$$

and the displacement vector $\boldsymbol{u}=[x, z]^{\mathrm{T}}$.

The governing equation of moisture transfer can therefore be written in the form of primary variables as

$$
\begin{aligned}
& C_{1 \mathrm{u}} \frac{\partial \boldsymbol{u}}{\partial t}+C_{1 \mathrm{~T}} \frac{\partial T}{\partial t}=\nabla\left(K_{11} \nabla u_{1}\right)+\nabla\left(K_{\mathrm{lT}} \nabla T\right)+J_{1} \\
& \boldsymbol{C}_{\mathrm{lu}}=\boldsymbol{m}^{\mathrm{T}} \boldsymbol{P} \\
& C_{\mathrm{lT}}=\frac{\rho_{\mathrm{i}}-\rho_{1}}{\rho_{1}\left(1-S_{\mathrm{i}}\right)+\rho_{\mathrm{i}} S_{\mathrm{i}}} n \frac{\partial S_{\mathrm{i}}}{\partial T} \\
& K_{11}=\frac{1}{\rho_{1}\left(1-S_{\mathrm{i}}\right)+\rho_{\mathrm{i}} S_{\mathrm{i}}} \frac{k_{1}}{g} \\
& K_{\mathrm{IT}}=\frac{\rho_{1} L}{T_{0}} \frac{1}{\rho_{1}\left(1-S_{\mathrm{i}}\right)+\rho_{\mathrm{i}} S_{\mathrm{i}}} \frac{k_{1}}{g} \\
& J_{1}=\frac{\rho_{1}}{\rho_{1}\left(1-S_{\mathrm{i}}\right)+\rho_{\mathrm{i}} S_{\mathrm{i}}} \nabla\left(k_{1} \nabla z\right)
\end{aligned}
$$

Note that the second term of the left-hand side (LHS) in equation (10a) represents the volumetric change due to pore water phase change. The first and second terms of the righthand side (RHS) contribute to the water flow driven by pore pressure gradient and temperature gradient respectively.

\section{Heat transfer}

The law of energy conservation of heat for freezing soils can be expressed as

$$
\frac{\partial(\Phi \mathrm{d} V)}{\partial t}+\nabla \boldsymbol{Q} \mathrm{d} V=0
$$

where $\Phi$ refers to the heat content of soil per unit volume, defined as

$$
\Phi=H_{\mathrm{c}}\left(T-T_{\mathrm{r}}\right)-\operatorname{Ln} S_{\mathrm{i}} \rho_{\mathrm{i}}
$$

where $H_{\mathrm{c}}$ is the volumetric heat capacity of the soil, defined as

$$
H_{c}=\left(1-S_{i}\right) n \rho_{l} c_{l}+n S_{i} \rho_{i} c_{i}+(1-n) \rho_{s} c_{s}
$$

where $c_{1}, c_{\mathrm{i}}$ and $c_{\mathrm{s}}$ are the specific heat capacities of pore water, ice and the solid particles respectively; $\rho_{\mathrm{s}}$ is the density of soil particles; and $T_{\mathrm{r}}$ is the reference temperature. $Q$ is the heat flux per unit volume, including conduction and pore water convection, and is defined as

$$
\boldsymbol{Q}=-\lambda_{\mathrm{T}} \nabla T+c_{1} \rho_{1} \boldsymbol{v}_{\mathrm{l}}\left(T-T_{\mathrm{r}}\right)
$$


where $\lambda_{\mathrm{T}}$ is the thermal conductivity of the soil, which can be written as

$$
\lambda_{\mathrm{T}}=\left(1-S_{\mathrm{i}}\right) n \lambda_{1}+n S_{\mathrm{i}} \lambda_{\mathrm{i}}+(1-n) \lambda_{\mathrm{s}}
$$

where $\lambda_{1}, \lambda_{\mathrm{i}}$ and $\lambda_{\mathrm{s}}$ are the thermal conductivities of pore water, ice and the solid particles respectively. The governing equation of heat transfer can be finally written in the form of primary variables by substituting equations (12) and (13) into equation (11) to give

$$
\begin{aligned}
& \boldsymbol{C}_{\mathrm{Tu}} \frac{\partial \boldsymbol{u}}{\partial t}+C_{\mathrm{TT}} \frac{\partial T}{\partial t}=\nabla\left(K_{\mathrm{Tl}} \nabla u_{1}\right)+\nabla\left(K_{\mathrm{TT}} \nabla T\right)+J_{\mathrm{T}} \\
& \boldsymbol{C}_{\mathrm{Tu}}=\left\{\left[\left(1-S_{\mathrm{i}}\right) \rho_{1} c_{1}+S_{\mathrm{i}} \rho_{\mathrm{i}} c_{\mathrm{i}}\right]\left(T-T_{\mathrm{r}}\right)-S_{\mathrm{i}} \rho_{\mathrm{i}} L\right\} \boldsymbol{m}^{\mathrm{T}} \boldsymbol{P} \\
& C_{\mathrm{TT}}=H_{\mathrm{c}}+\left[\left(\rho_{\mathrm{i}} c_{\mathrm{i}}-\rho_{1} c_{1}\right)\left(T-T_{\mathrm{r}}\right)-\rho_{\mathrm{i}} L\right] n \frac{\partial S_{\mathrm{i}}}{\partial T} \\
& K_{\mathrm{Tl}}=\frac{c_{1} k_{1}}{g}\left(T-T_{\mathrm{r}}\right) \\
& K_{\mathrm{TT}}=\lambda_{\mathrm{T}}+\frac{\rho_{1} L}{T_{0}} \frac{c_{1} k_{1}}{g}\left(T-T_{\mathrm{r}}\right) \\
& J_{\mathrm{T}}=c_{1} \rho_{1}\left(T-T_{\mathrm{r}}\right) \nabla\left(k_{1} \nabla z\right)
\end{aligned}
$$

Note that the first and second terms of the RHS of equation (16a) include the heat convection of the water flow.

\section{Force equilibrium}

Stress equilibrium for non-isothermal small deformation soils can be expressed as

$$
\frac{\partial\left(\mathrm{d} \sigma_{i j}\right)}{\partial x_{j}}+\mathrm{d} b_{i}=0
$$

where $b_{i}$ refers to the body force, and $\sigma_{i j}$ is the total stress tensor, which can be written according to the effective stress principle (Terzaghi, 1943) as

$$
\sigma_{i j}=\sigma_{i j}^{\prime}+\delta_{i j} u_{1}
$$

where $\sigma_{i j}^{\prime}$ is the effective stress tensor and $\delta_{i j}$ refers to the Kronecker tensor. In the partially frozen soil it is assumed that the pore ice does not form a continuous phase and is unable to exert a mechanical pressure. However, when the soil is fully frozen the pore ice is continuous, and the pore water pressure $u_{1}$ effectively represents the mechanical ice pressure. Here the compression positive sign convection for normal stress is chosen. The total strain for freezing soils is assumed to consist of components due to effective stress change and temperature change,

$$
\mathrm{d} \boldsymbol{\varepsilon}=\mathrm{d} \boldsymbol{\varepsilon}_{\sigma^{\prime}}+\mathrm{d} \boldsymbol{\varepsilon}_{T}
$$

where the subscripts $\sigma^{\prime}$ and $T$ refer to the effective stress and temperature respectively. The incremental total strain can be written in the form of the primary variables as

$$
\mathrm{d} \boldsymbol{\varepsilon}=\boldsymbol{P} \mathrm{d} \boldsymbol{u}
$$

The thermal expansion is assumed proportional to the temperature change, and the incremental thermal volumetric strain will be

$$
\mathrm{d} \varepsilon_{\mathrm{T}}=\alpha_{\mathrm{T}} \boldsymbol{m} \mathrm{d} T=\boldsymbol{A}_{\mathrm{T}} \mathrm{d} T
$$

where $\alpha_{\mathrm{T}}$ is the thermal expansion coefficient, which may be dependent on the water content and the temperature of the soil; and $\boldsymbol{A}_{\mathrm{T}}$ is the thermal vector, defined as

$$
\boldsymbol{A}_{\mathrm{T}}=\alpha_{\mathrm{T}} \boldsymbol{m}
$$

A linear elastic stress-strain relationship is assumed for freezing soils and is written, in an incremental form, as $\mathrm{d} \boldsymbol{\sigma}^{\prime}=\boldsymbol{D} \mathrm{d} \boldsymbol{\varepsilon}_{\sigma^{\prime}}$

where $\boldsymbol{\sigma}^{\prime}$ is the effective stress vector and $\boldsymbol{D}$ is the standard elastic matrix (Zienkiewicz \& Taylor, 2000).

The governing equation of force equilibrium can be finally written in the form of primary variables as

$$
\begin{aligned}
& \boldsymbol{C}_{\mathrm{uu}} \mathrm{d} \boldsymbol{u}+\boldsymbol{C}_{\mathrm{ul}} \mathrm{d} u_{1}+\boldsymbol{C}_{\mathrm{uT}} \mathrm{d} T+\mathrm{d} \boldsymbol{b}=0 \\
& \boldsymbol{C}_{\mathrm{uu}}=\boldsymbol{P}^{\mathrm{T}} \boldsymbol{D} \boldsymbol{P} \\
& \boldsymbol{C}_{\mathrm{ul}}=-\boldsymbol{P}^{\mathrm{T}} \boldsymbol{m} \\
& \boldsymbol{C}_{\mathrm{uT}}=-\boldsymbol{P}^{\mathrm{T}} \boldsymbol{D} \boldsymbol{A}_{\mathrm{T}} \\
& \boldsymbol{b}=\left[\begin{array}{ll}
b_{x} & b_{z}
\end{array}\right]^{\mathrm{T}}
\end{aligned}
$$

Governing equations for freezing soils can be reduced to those for unfrozen and fully frozen soils. In these cases the terms considering water flow driven by the cryogenic suction related to water/ice interface tension do not exist. For unfrozen soils, $\rho_{\mathrm{i}}=\rho_{1}$ and $S_{\mathrm{i}} \equiv 0$ are set in the governing equations. For fully frozen soils, $\rho_{1}=\rho_{\mathrm{i}}$ and $S_{\mathrm{i}} \equiv 1$ are set in the governing equations.

Consequently, the partial differential equations (equations (10), (16) and (24)) are available to describe moisture transfer, heat transfer and force equilibrium in freezing soils, and are integrated into a finite element program called COMPASS, which has been shown to provide stable solutions to highly non-linear problems (Thomas \& He, 1995, 1997).

\section{Ice segregation}

A stress criterion for initiating a new ice lens is adopted by many researchers (Miller, 1978; Gilpin, 1980; O’Neill \& Miller, 1985; Nixon, 1991) to determine when and where a new ice lens forms. Such approaches consider that in a onedimensional case the soil skeleton separates and a new ice lens forms when the pore pressure exceeds the sum of the overburden stress $p_{\mathrm{ob}}$ and the separation strength of the freezing soil $p_{\text {sep }}$ : that is, the vertical effective stress is less than $-p_{\text {sep }}$ (tension),

$$
\sigma_{z}^{\prime} \leqslant-p_{\text {sep }}
$$

For typical seasonal freezing situations $p_{\text {sep }}$ is in the range 20-150 kPa (Tsytovich, 1975; Mackay, 1980; Nixon, 1991). Such an approach could be developed into a more generalised form by way of consideration of the strain field, for example by extending the one-dimensional strain criterion approach proposed by Konrad \& Duquennoi (1993). However, in this study the stress criterion approach defined by equation (25) has been adopted. It should be noted, however, that such an approach still allows consideration of many situations found in seasonally frozen soils where the direction of major principal stress, in the unfrozen soil, coincides with the direction of the frozen front movement. It has also been observed that, immediately after a new ice lens is initiated, the local pore pressure falls to the overburden stress (Konrad \& Morgenstern, 1980; Nixon, 1991).

The algorithm of the standard transient finite element method has been modified to identify the moment when ice segregation takes place with a stress-checking scheme after the computation for each time step is completed. If the effective stress at a particular depth has become lower than the separation strength (as shown in equation (25)), that particular time step is recalculated with a reduced time increment to ensure that at that location the effective stress equals the separation strength at the end of the time step. This allows the algorithm to record the time at which an ice lens forms, and its location. To represent the damage to the 
soil structure once ice segregation takes place, the local Young's modulus is reduced to an extremely low value and the vertical effective stress is set to zero; numerical iterations are then carried out to perform force redistribution in the soil. After the inception of each new lens the time step is reset back to the original time step.

\section{APPLICATION OF MODEL TO TYPICAL CONDITIONS}

In this section the proposed model is applied to the idealised cases of a soil column subjected to both one- and two-sided freezing regimes, which correspond to freezing processes of a seasonally frozen soil and a soil layer overlying permafrost respectively. The initial water content of the $10 \mathrm{~cm}$ soil column is $20 \%$, and the coefficient for the degree of moisture with respect to ice, $\alpha=-5 \cdot 0$. The hydraulic conductivity parameters of $k_{10}=5 \times 10^{-10} \mathrm{~m} / \mathrm{s}$ and $\beta=-8.0$ are adopted to represent a typical soil such as a Calgary silty clay (Patterson \& Smith, 1981). The heat capacity and the thermal conductivity of soil solid particles are taken as $c_{\mathrm{s}}=800 \mathrm{~J} / \mathrm{kg} \mathrm{K}$ and $\lambda_{\mathrm{s}}=1.2 \mathrm{~J} / \mathrm{m} \mathrm{s} \mathrm{K}$ respectively. A shear modulus of $G=0.5 \mathrm{MPa}$, Poisson's ratio of $v=0.3$ and thermal expansion coefficient of zero are used for the soil. Additional parameters are listed in Table 1. A uniform finite element mesh with 100 twelve-node quadrilateral elements and a time step of $60 \mathrm{~s}$ are adopted to discretise the problem in the spatial domain and temporal domain respectively: these have been found to yield converged results. It is recognised that in the one-sided freezing examples the strains developed are particularly large, and that the use of a large-strain formulation would improve the accuracy of the solution.

\section{One-sided typical freezing condition}

In this case the column is initially unfrozen, with a temperature of $0.5^{\circ} \mathrm{C}$ throughout. The top surface temperature is then reduced to $-2^{\circ} \mathrm{C}$, to trigger the freezing process, and remains at that value; the temperature at the base is kept at $0.5^{\circ} \mathrm{C}$ throughout. Water is freely available at the base: that is, the pore pressure is held at zero throughout the freezing process. This is typical of a soil layer underlain by a more permeable soil layer with a readily accessible water table.

Four parametric analyses are performed, with overburden pressures of 50 and $200 \mathrm{kPa}$ and separation strengths of 25 and $50 \mathrm{kPa}$ considered. Typically it has been observed that reduced overburden pressures and separation strengths lead to a system that is more prone to (a) ice lensing in the frozen fringe and (b) greater frost heave. It can be seen in Fig. 5 that an increase in the overburden pressure results in a dramatic reduction in the frost heave. Higher separation strength also causes less frost heave, but it does not affect the frost heave as strongly as the overburden pressure. It can

Table 1. Physical parameters for modelling freezing soils

\begin{tabular}{l|c}
\hline Parameter & Value \\
\hline Density of water, $\rho_{1}: \mathrm{kg} / \mathrm{m}^{3}$ & 1000 \\
Density of ice, $\rho_{\mathrm{i}}: \mathrm{kg} / \mathrm{m}^{3}$ & 917 \\
Heat capacity of water, $c_{1}: \mathrm{J} / \mathrm{kg} \mathrm{K}$ & 4180 \\
Heat capacity of ice, $c_{\mathrm{i}}: \mathrm{J} / \mathrm{kg} \mathrm{K}$ & 2044 \\
Thermal conductivity of water, $\lambda_{\mathrm{l}}: \mathrm{J} / \mathrm{m} \mathrm{s} \mathrm{K}$ & $0 \cdot 58$ \\
Thermal conductivity of ice, $\lambda_{\mathrm{i}}: \mathrm{J} / \mathrm{m} \mathrm{s} \mathrm{K}$ & $2 \cdot 22$ \\
Latent heat of fusion for water, $L: \mathrm{J} / \mathrm{kg}$ & 334000 \\
Reference temperature, $T_{\mathrm{r}}: \mathrm{K}$ & 293 \\
Acceleration due to gravity, $g: \mathrm{m} / \mathrm{s}^{2}$ & $9 \cdot 81$ \\
\hline
\end{tabular}

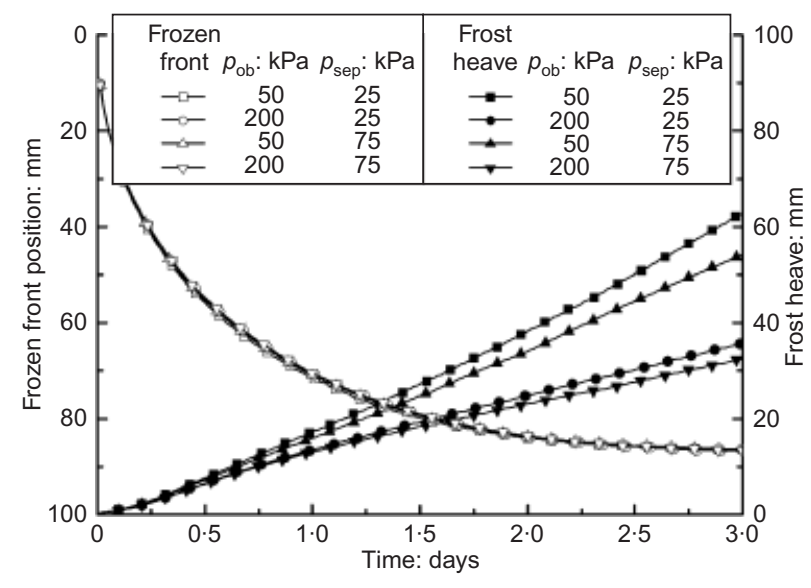

Fig. 5. Frozen front position and frost heave for typical onesided freezing condition

also be seen that the penetration of the freezing front is not sensitive to overburden pressure or separation strength.

The predicted ice lens distributions are illustrated in Fig. 6: the white and grey portions of the column represent ice lenses and the soils respectively. In the early stage, the freezing front advances downwards rapidly (Fig. 5), owing to a high thermal gradient near the cold side, and there is not sufficient time for the formation of visible ice lenses, although ice lenses are initiated. As the rate of the freezing front penetration decreases, as a consequence of the decreasing thermal gradient, larger ice lenses at a greater spacing form progressively in the column. It can be seen that a higher overburden pressure and separation strength lead to thicker ice lenses with greater spacing. Such predicted ice lens distributions are consistent with experimental observations in step-freezing tests (Konrad, 1994), whose cold and warm sides are maintained at constant temperatures during the complete test.

Temperature, pore pressure and water velocity profiles at $t=0.75$ day, for the typical one-sided freezing condition, with $p_{\mathrm{ob}}=50 \mathrm{kPa}$ and $p_{\text {sep }}=25 \mathrm{kPa}$ are shown in Figs 7 and 8 . It should be noted that positive velocities in Fig. 8 refer to upward water flow. The temperature profile is nearly linear in both the fully frozen and unfrozen sections of the column, whereas in the frozen fringe it exhibits a non-linear profile owing to the changing thermal conductivity (Fig. 7).

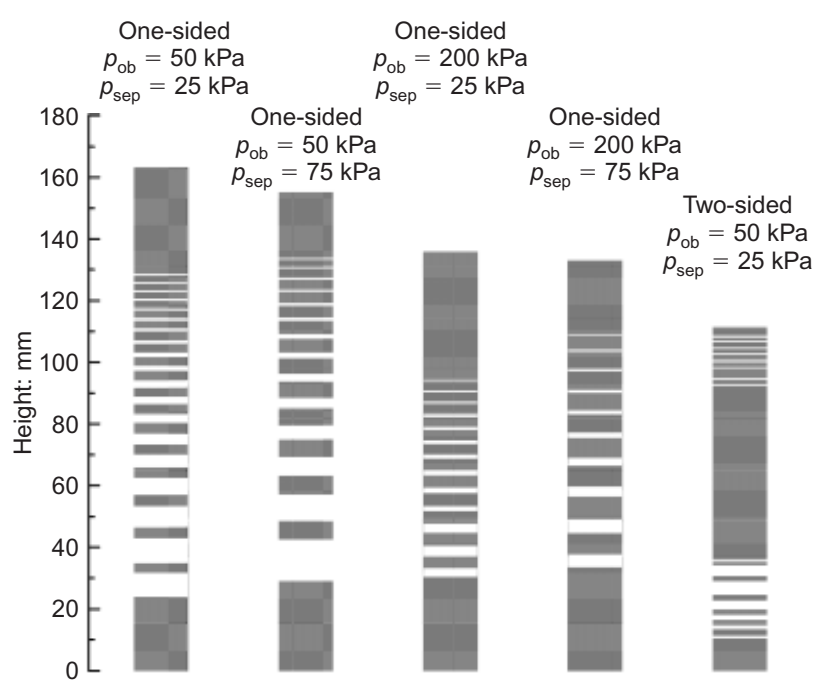

Fig. 6. Predicted ice lens distributions for typical freezing condition (white: ice lens region) 


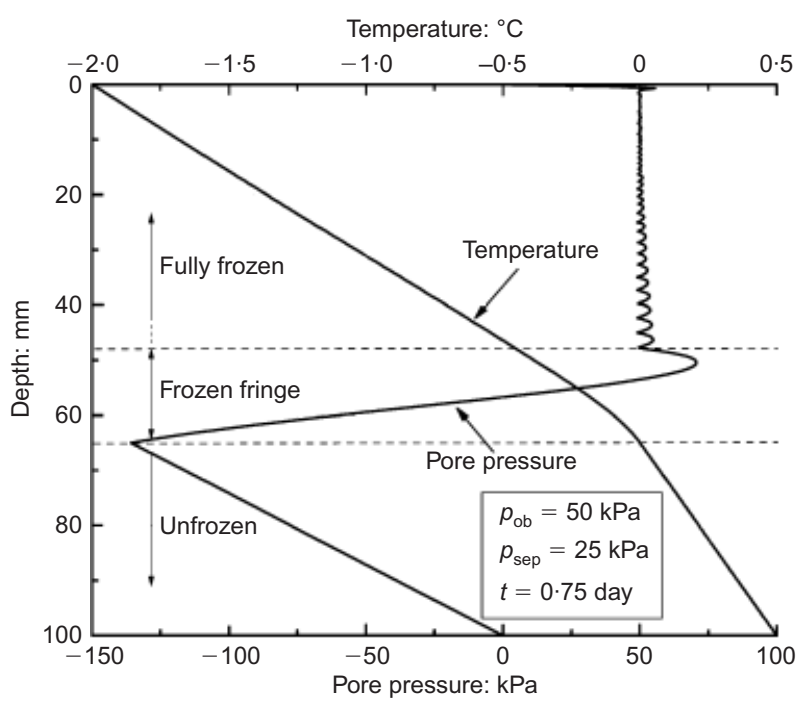

Fig. 7. Temperature and pore pressure profiles for typical onesided freezing condition

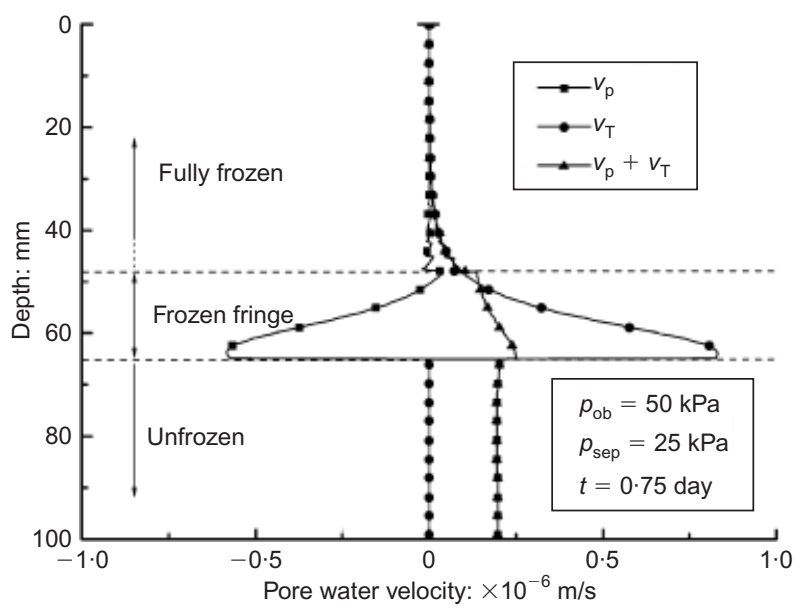

Fig. 8. Pore water velocity profiles for typical one-sided freezing condition $\left(v_{\mathrm{p}}\right.$, pore water velocity due to pore water pressure gradients; $v_{\mathrm{T}}$, pore water velocity due to temperature gradients)

As seen in Fig. 7, in the region of the frozen fringe the development of a gradient of cryogenic suction results both in an opposing development of a pore pressure gradient that, to some degree, counteracts the upward water flow drawn by the cryogenic suction (Fig. 8), and in a large negative pore pressure at the base of the fringe. When the pore pressure reaches $p_{\mathrm{ob}}+p_{\text {sep }}$ a new ice lens is initiated in the frozen fringe according to the stress criterion (i.e. equation (25)), as shown in Fig. 7. After the ice lens has initiated and ice starts to accumulate, the elevated pore pressure is relieved and falls to a value of $p_{\mathrm{ob}}$. At the base of the frozen fringe the large negative pore pressure that has developed results in an almost constant pore pressure gradient in the unfrozen soil, with water drawn towards the frozen fringe from the open water supply at the bottom boundary at a near-constant velocity.

The displacement profile for the typical one-sided freezing condition with $p_{\mathrm{ob}}=50 \mathrm{kPa}$ and $p_{\text {sep }}=25 \mathrm{kPa}$ is shown in Fig. 9. The steps in the fully frozen portion represent the places where ice lenses form. The ice lenses are very thin near the cold side, and not visible in Fig. 6. The displacement is negative under the frozen fringe as a result of consolidation. Such consolidation of the soil below a frozen

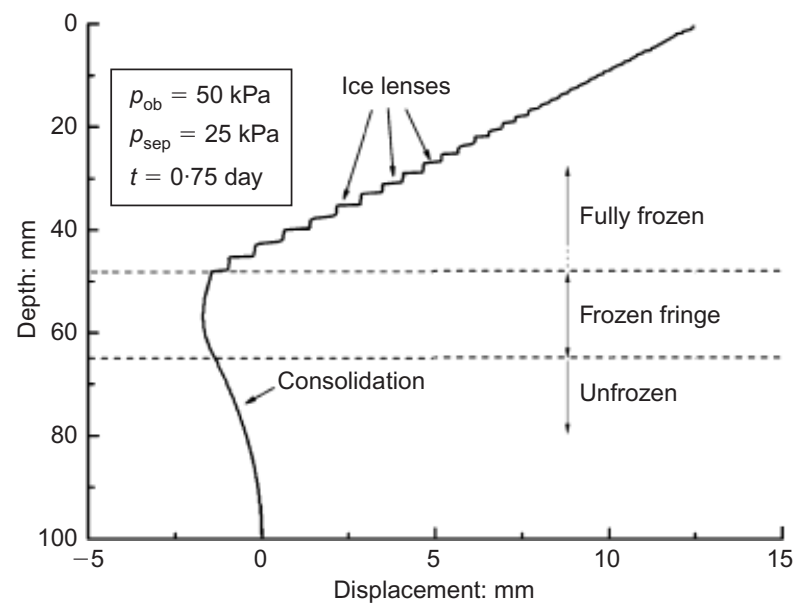

Fig. 9. Displacement profile for typical one-sided freezing condition

fringe with a forming ice lens has been observed experimentally (Ono, 2002).

\section{Two-sided typical freezing condition}

In this case the temperatures at the top and the base are initially $6^{\circ} \mathrm{C}$ and $-1.5^{\circ} \mathrm{C}$ respectively, with a linear profile between the top and the base. The temperatures at the top and base of the column are then held constant for two days to model a permafrost situation during summer periods. A flux of water is supplied at the top surface during the times $1-1 \cdot 25$ days and $1 \cdot 75-2$ days to represent rainfall, and to allow the process of summer heave (Mackay, 1983) to be considered. The temperature at the top of the column is then reduced to $-2^{\circ} \mathrm{C}$ after 2 days and subsequently held at that value to model winter freezing. Apart from the two rainfalls there is no other water supply at the boundaries.

Initially there is a frozen fringe near the base due to the thermal profile: this results in pore water in the upper portion being drawn downwards towards the frozen fringe, and subsequent ice lens formation in the lower portion, leading to frost heave, as shown in Fig. 10. When rainfall is simulated on the top surface of the column, the water is drawn quickly towards the frozen fringe and develops thicker ice lenses (Fig. 6), causing summer heave (Fig. 10), consistent with observed behaviour (Mackay, 1983).

In the summer period there is only one freezing front, which is near the base, as shown in Fig. 10. This freezing

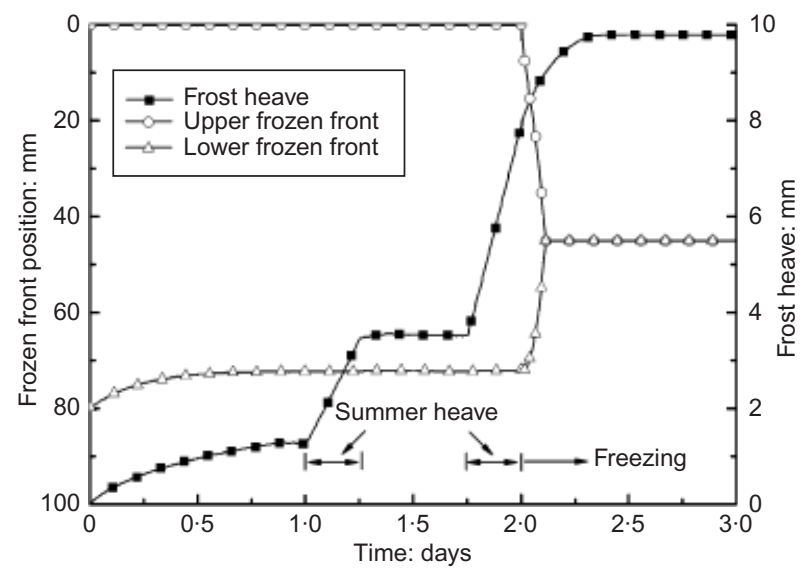

Fig. 10. Frozen front position and frost heave for typical two-sided freezing condition 
front moves upwards in the early stage, as a result of changes in the thermal conductivity profile related to ice lens formation and phase change, and is then stationary until the freezing condition is applied to the top of the column. Then the freezing front moves upwards owing to a flux of thermal energy towards the surface of the column. Simultaneously, a new freezing front is developed in the upper portion and moves downwards quickly. These two freezing fronts meet after $2 \cdot 15$ days, and at this point the whole column is below $0^{\circ} \mathrm{C}$.

Temperature and pore pressure profiles for the two-sided freezing case after $2 \cdot 1$ days are shown in Fig. 11. The temperature remains just above zero degree in the middle unfrozen portion as latent heat is released during water phase change: this so-called 'zero curtain' effect is a wellestablished phenomenon (Mackay, 1983; Outcalt et al., 1990). Also at this time high negative pore pressures can be found in the central section of the column as water is drawn upwards and downwards by the cryogenic suctions created in the two frozen fringes, and this effect can also be observed in the velocity profiles shown in Fig. 12. Finally, thick ice lenses and significant frost heave are found near the base, and only very thin ice lenses occur near the top surface, as shown in Fig. 13. Pore water loss and consolidation effects dominate in the middle portion of the column.

\section{SMALL-SCALE PHYSICAL TESTS}

Two small-scale laboratory freezing and thawing tests have been performed that consider cases of both one-sided and two-sided freezing. Initially, results of the tests are

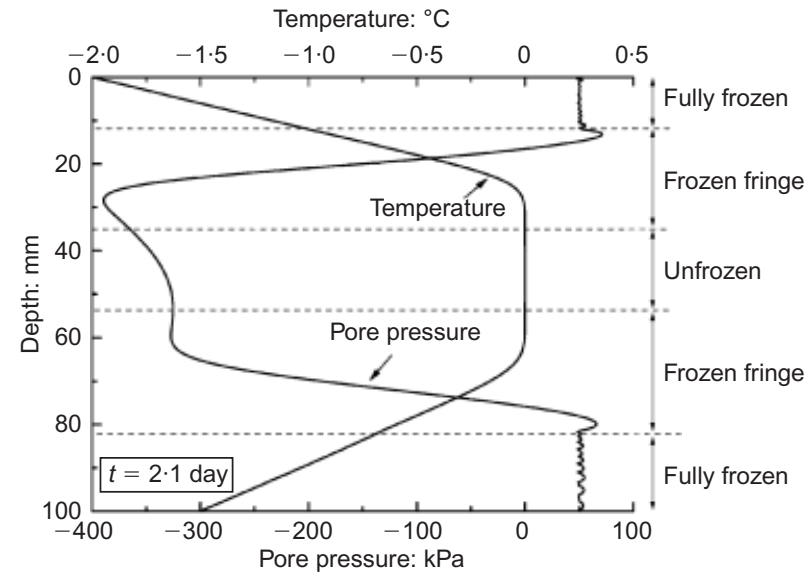

Fig. 11. Temperature and pore pressure profiles for typical two-sided freezing condition

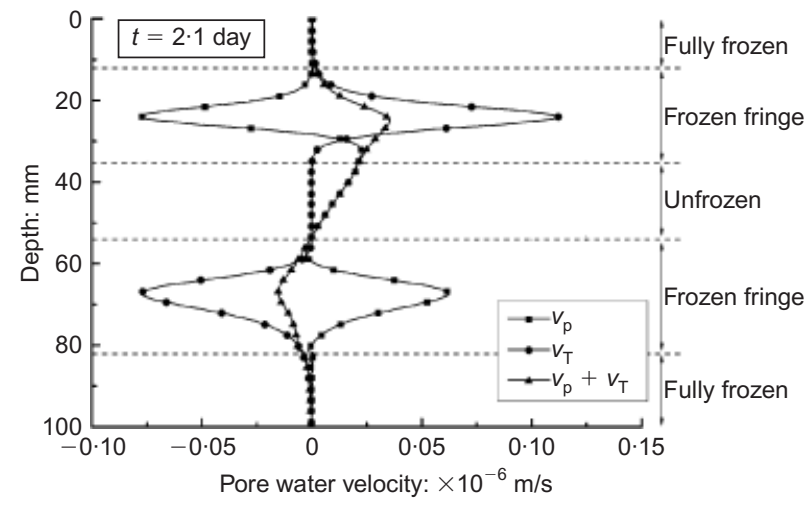

Fig. 12. Pore water velocity profiles for typical two-sided freezing condition

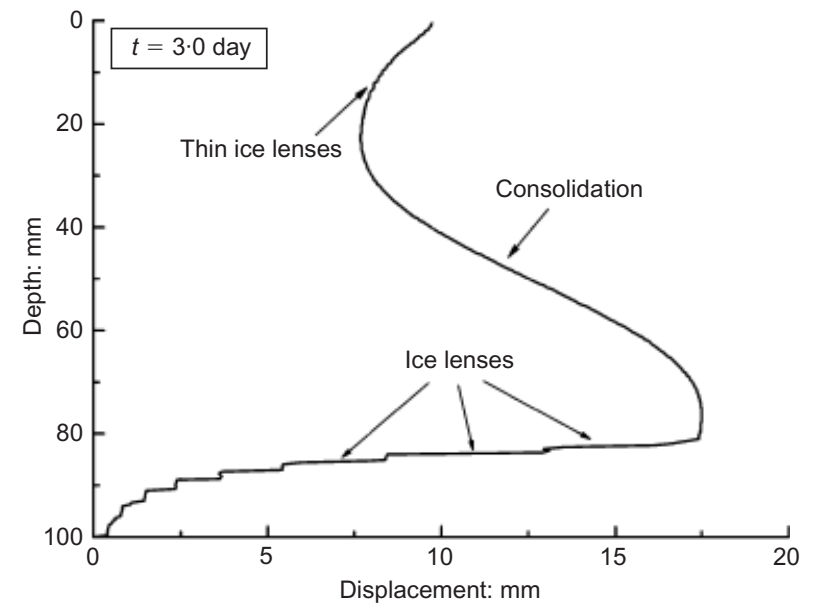

Fig. 13. Displacement profile for typical two-sided freezing condition

presented; then the proposed model is applied to simulate the initial freezing of the sample, and comparisons are made.

The soil models are constructed in Perspex boxes with a frost-susceptible silty soil. Further details are given in KernLuetschg et al. (2008). Fig. 14 shows the model design, with a soil layer placed over a basal sand layer. The soil layer has a thickness of $9 \mathrm{~cm}$ for the one-sided test and $14 \mathrm{~cm}$ for the two-sided test, and a confining load of $1.5 \mathrm{kPa}$ is applied on the surface of the sample. The model slope gradient was $12^{\circ}$ in both cases; however, during freezing the samples were tilted at $12^{\circ}$, resulting in the soil surface being horizontal in this phase of the test. An open water system was provided through the basal sand layer for the one-sided test, thereby

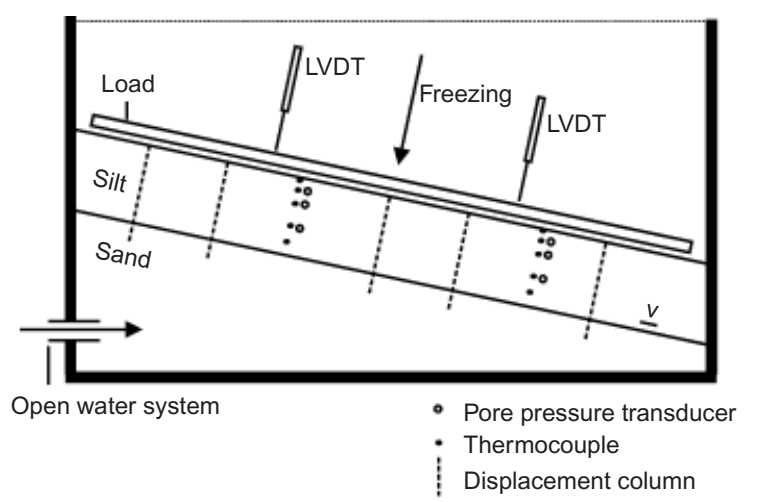

(a)

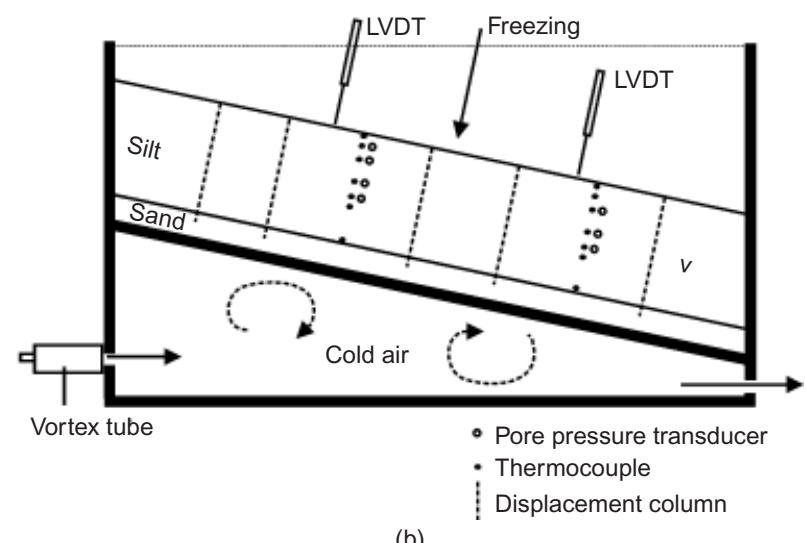

(b)

Fig. 14. Experimental design for: (a) one-sided freezing and (b) two-sided freezing 
allowing ice segregation in the soil layer, with the water level maintained at the soil/sand interface during freezing. For the two-sided test a cold permafrost table was simulated using a basal cooling system to allow the unfrozen layer to freeze from the permafrost table upwards as well as from the surface downwards. During the first $24 \mathrm{~h}$ of the test, water was sprinkled on to the surface of the soil to allow summer frost heave to develop. Type $\mathrm{K}$ thermocouples (at depths $0,3 \cdot 5,6$ and $7 \mathrm{~cm}$ in the one-sided test and 2, 3.5, 6, 8,9 and $12 \mathrm{~cm}$ in the two-sided test) were inserted to monitor the temperatures, and linear voltage transducers were placed perpendicular to the soil surface to record frost heave during freezing.

Transient frost heave and temperature variations are presented in Figs 15 and 16 for the one-sided and two-sided freezing tests respectively. It can be observed that the development of frost heave is significantly different between the two tests. A uniform frost-heaving rate is observed in the one-sided test, indicating uniform ice segregation throughout the soil. However, in the two-sided experiment, where basal temperatures were constantly kept below zero, the frost heaving rate is more varied, and strongly influenced by the addition of water at the surface and the associated summer heave. In the one-sided model, surface downwards freezing is indicated by the temperature-time series at depths $0,1,3.5$ and $7 \mathrm{~cm}$. The development of a pseudo-

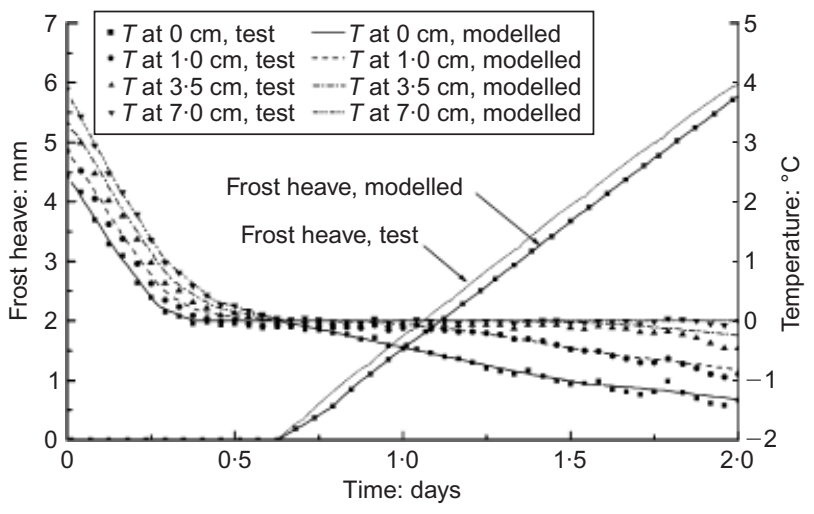

Fig. 15. Frost heave and temperature with time for one-sided freezing small scale test isothermal (at $\sim 0^{\circ} \mathrm{C}$ ) condition in the soil before the surface temperature drops below $0^{\circ} \mathrm{C}$ can be seen. In the two-sided experiment the thermal regime is more complex, with active freezing taking place both at the surface and at the base of the sample.

The frozen model slopes were then placed in a geotechnical centrifuge and thawed under a vertical gravitational field of $10 \mathrm{~g}$. Thawing was from the soil surface downwards at air temperatures between $10^{\circ} \mathrm{C}$ and $15^{\circ} \mathrm{C}$ and with an open drainage system. Each model was subjected to five freezethaw cycles, after which displacement columns were excavated. Fig. 17 shows the displacement column profile for (a) the one-sided and (b) two-sided experiments. Two distinct styles of behaviour can be seen, with progressive downslope movement in the one-sided experiment and more 'plug-like' movement in the two-sided experiment. Such plug-like movement has been characterised by Mackay (1981) for the case where the surface displacement is very small as the thaw front penetrates through the upper layers of the slope, but is then markedly increased during melting of the basal

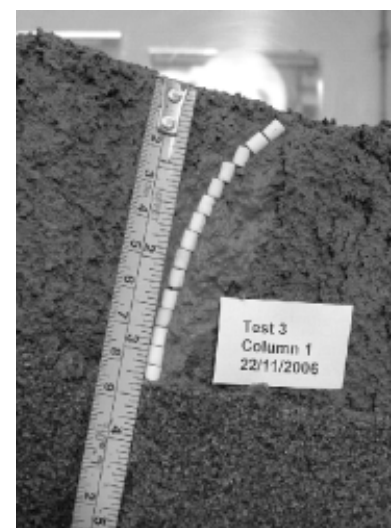

(a)

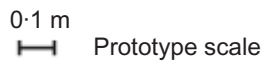

$\stackrel{0.1 \mathrm{~m}}{\longmapsto}$ Prototype scale

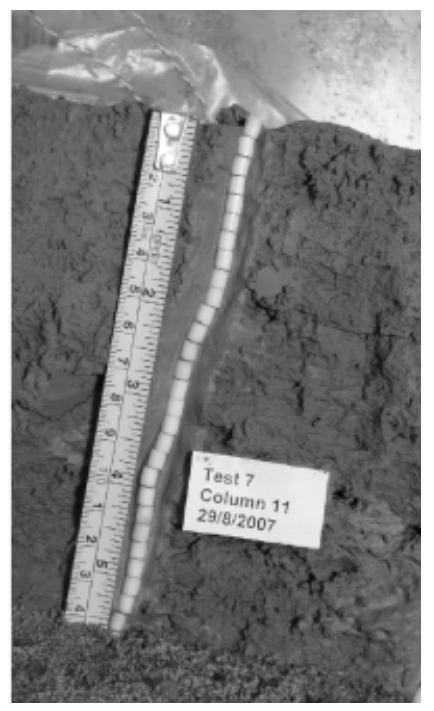

(b)
Fig. 17. Observed sub-surface displacement for: (a) one-sided and (b) two-sided experiment

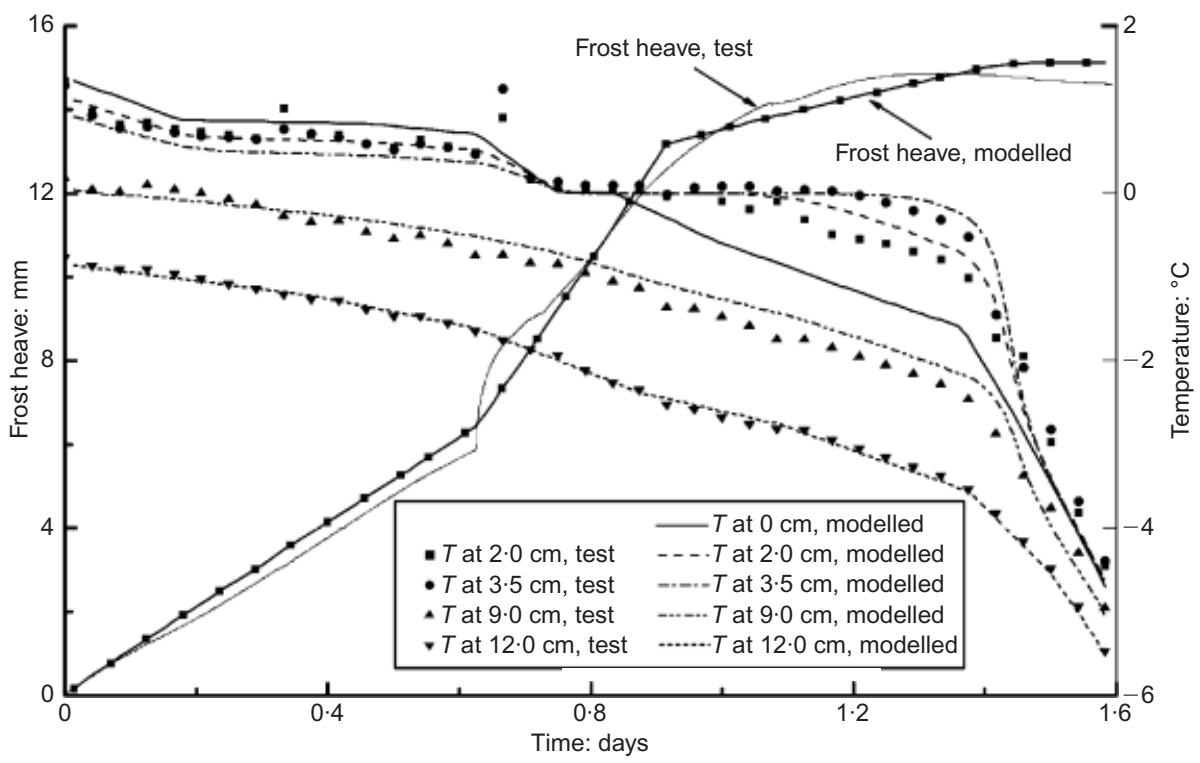

Fig. 16. Frost heave and temperature with time for two-sided freezing small scale test 
ice-rich zone, giving considerable surface movement late in the thaw period, with the soil mass above the location of the basal ice-rich zone moving as a single mass or plug. These observed profiles are of value in terms of assessing the locations of ice-rich soil layers as the presence of ice lenses and downslope displacement profiles are closely correlated (Harris et al., 2008a, 2008c; Kern-Luetschg et al., 2008). In these studies the locations of ice-rich content, formed in the freezing process, have been identified by way of detailed analysis of both the thermal field and the development of vertical displacements. In particular, a strong correlation is found both between movement of the freezing front and frost-heaving rates and between shear strain and volume strain during thaw. Further analysis clearly shows that the depth at which high downslope shear strain occurs is consistent with these identified locations of ice-rich content.

The freezing stages of each of the two tests have been simulated by the proposed model, and results of these analyses are presented below. In each test the porosity of the silty soil has been determined as $35 \%$, the hydraulic conductivity for the fully unfrozen state is estimated as $k_{10}=$ $1.0 \times 10^{-8} \mathrm{~m} / \mathrm{s}$ with $\beta=-40 \cdot 0$, the shear modulus is taken as $G=1.0 \mathrm{MPa}$, and a separation strength $p_{\text {sep }}=75 \mathrm{kPa}$ is adopted. The remaining parameters are as used in the previous section. For each analysis a representative column of soil has been considered, and discretised with a uniform finite element mesh of $1 \mathrm{~mm}$ high 12-node quadrilateral elements and a time step of $60 \mathrm{~s}$. This discretisation of the problem in the temporal and spatial domains has been found to yield converged results.

In the one-sided freezing small-scale test a two-day period before the temperature at $7 \mathrm{~cm}$ drops below the freezing point is considered, as the temperature at the base of the soil layer $(9 \mathrm{~cm})$ is not available from the test. The temperatures of the top of the sample and the portion below $7 \mathrm{~cm}$ are fixed with those measured experimentally at depths of $0 \mathrm{~cm}$ and $7 \mathrm{~cm}$ respectively. A water influx of $3.5 \times 10^{-8} \mathrm{~m}^{3} / \mathrm{s}$ per unit area is provided at the base of the soil layer after the freezing process starts, based on the measured heave rate in the test, to represent the open water system in the basal sand layer.

The predicted temperatures at depths of $1 \mathrm{~cm}$ and $3.5 \mathrm{~cm}$ are in good agreement with those monitored in the test, as shown in Fig. 15. The predicted distribution of ice lenses near the surface is almost uniform, as shown in Fig. 18, and is consistent with the linear thaw settlement rate and the downslope movement profile monitored in the test, shown in Fig. 17.

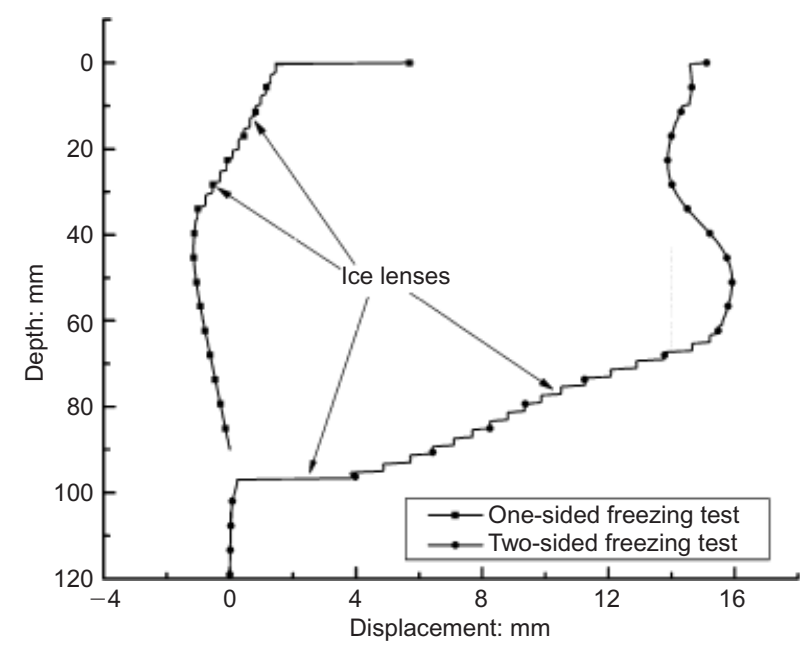

Fig. 18. Predicted vertical displacement profiles for small scale tests
Freezing of the soil layer over a 1.6 day period of the two-sided freezing small-scale test is considered here. The temperature at the base of the soil layer is fixed at the temperature measured at the depth of $12 \mathrm{~cm}$ during the test, as shown in Fig. 16. As the temperature at the surface of sample was not monitored, a time-dependant fixed boundary condition has been applied at the surface of the soil, based on an interpolation between the measured air temperature and the temperature measured at $2 \mathrm{~cm}$, as shown in Fig. 16 . A water flux is supplied at the surface of the column during the first $24 \mathrm{~h}$ to model the addition of water sprinkled onto the surface of the soil during the test, and a zero flux boundary condition is applied at the base to represent the impact of the permafrost layer in the lower portion.

The calculated temperature-time curves before $1 \cdot 2$ days at depths of $2 \mathrm{~cm}, 3.5 \mathrm{~cm}$ and $9 \mathrm{~cm}$ are quite close to those monitored in test, as shown in Fig. 16. However, the calculated temperatures fall later than the test after 1.2 days when the freezing front advances towards the middle of the soil layer. The reason is that the soil was observed to desaturate to some degree in the test, whereas the soil is assumed to be fully saturated in the proposed model. Therefore in the numerical modelling more water is present in this central region, and more energy is required to be released to allow water phase change to occur, thereby delaying the temperature drop.

An ice-rich portion between $6 \mathrm{~cm}$ and $10 \mathrm{~cm}$ is predicted in numerical modelling, as shown in Fig. 18, and it corresponds to the zone where the plug-like downslope movement occurred during the thaw phase in the test, shown in Fig. 17.

No drainage systems were available at the soil surface in the tests, and the water migrated from below accumulated and froze near the surface during downward freezing. An ice lens is obtained at the surface in the numerical modelling for both the tests, as shown in Fig. 18. It can be seen that, while water influx simulating rainfall in the two-sided test results in greater overall heave, a larger ice lens is calculated in the one-sided test.

\section{CONCLUSIONS}

This paper presents an investigation of the behaviour of soils subjected to seasonal temperature variations in both permafrost and seasonally frozen conditions. Numerical modelling of soil freezing and ice segregation processes is presented, and compared against small-scale experiments. The coupled THM model presented, which is solved by way of a transient finite element approach, considers several processes, including conduction, convection, phase change, the movement of moisture due to cryogenic suctions and the development of ice lenses.

Two seasonal freezing scenarios have been considered, both in terms of typical conditions and as part of an experimental study. In particular, the two main freezing conditions found in the field are considered: one-sided freezing for soils with no permafrost, where freezing is from the surface downwards, and two-sided freezing for soils underlain by permafrost, where large thermal gradients in the uppermost permafrost layer can cause active layer freezing in two directions, from the permafrost table upwards and from the ground surface downwards. The experimental results presented show that, in the case of one-sided freezing, ice lens formation occurs as the freezing front advances downwards from the surface, and is limited by water supply. However, during two-sided freezing, ice segregation takes place in a closed system, with ice lenses accumulating at the base of the active layer and near the ground surface, leaving an intervening ice-poor zone. The proposed numerical model is able to represent the development of both the thermal 
field and the ice segregation observed in the physical models.

\section{ACKNOWLEDGEMENTS}

The financial support received from the UK Engineering and Physical Sciences Research Council through grant number GR/T22964 and technical support from Harry Lane in the geotechnical centrifuge laboratory are gratefully acknowledged.

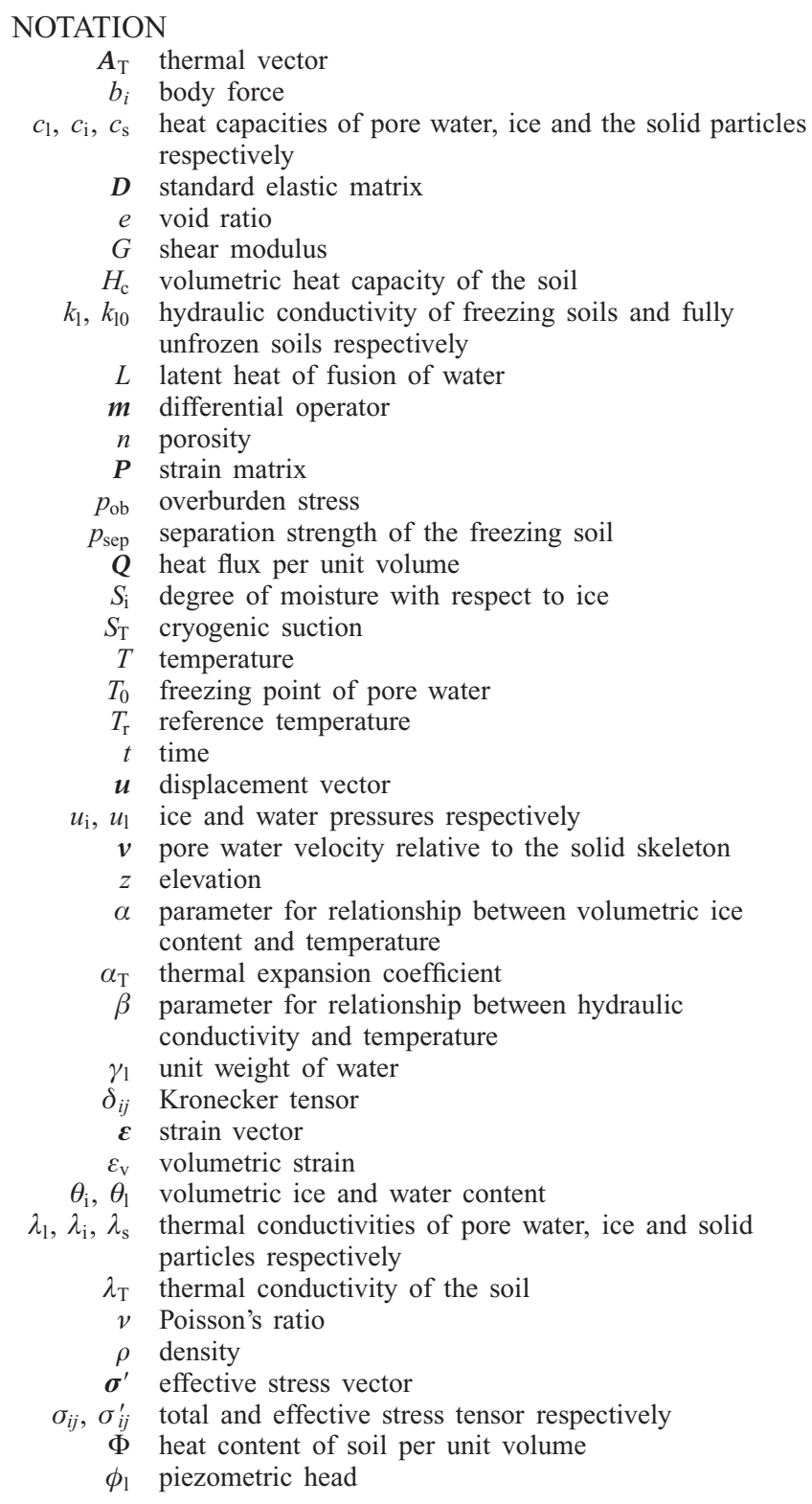

\section{REFERENCES}

Bear, J. \& Verruijt, A. (1987). Modeling groundwater flow and pollution. Dordrecht: Kluwer Academic.

Black, P. B. (1995). Application of the Clapeyron equation to water and ice in porous media. CRREL, US Army Corps of Engineers.

Gilpin, R. R. (1980). A model for the prediction of ice lensing and frost heave in soils. Water Resour. Res. 16, No. 5, 918-930.

Harris, C. (1996). Physical modelling of periglacial solifluction: review and future strategy. Permafrost Periglac. Process. 7, No. 4, 349-360.

Harris, C., Luetschg, M., Davies, M. C. R., Smith, F., Christiansen,
H. H. \& Isaksen, K. (2007). Field instrumentation for real-time monitoring of periglacial solifluction. Permafrost Periglac. Process. 18, No. 1, 105-114.

Harris, C., Kern-Luetschg, M. A., Murton, J. B., Font, M., Davies, M. C. R. \& Smith, F. W. (2008a) Full-scale physical modeling of solifluction processes associated with one-sided and two-sided active layer freezing. Proc. 9th Int. Conf. on Permafrost, Fairbanks, $A K, 663-668$.

Harris, C., Smith, J. S., Davies, M. C. R. \& Rea, B. (2008b) An investigation of periglacial slope stability in relation to soil properties based on physical modelling in the geotechnical centrifuge. Geomorphology 93, Nos. 3-4, 437-459.

Harris, C., Kern-Luetschg, M. A., Murton, J. B., Font, M., Davies, M. C. R. \& Smith, F. W. (2008c). Solifluction processes on permafrost and non-permafrost slopes: results of a large-scale laboratory simulation. Permafrost Periglac. Process. 19, No. 4, $359-378$.

Henry, K. S. (2000). A review of the thermodynamics of frost heave. CRREL, US Army Corps of Engineers.

Hoekstra, P. (1966). Moisture movement in soils under temperature gradients with the cold-side temperature below freezing. Water Resour. Res. 2, No. 2, 241-250.

Kern-Luetschg, M., Harris, C., Cleall, P. J., Li, Y.-C. \& Thomas, H. R. (2008). Scaled centrifuge modelling of solifluction in permafrost and seasonally frozen soils. Proc. 9th Int. Conf. on Permafrost, Fairbanks, AK, 919-924.

Konrad, J. M. (1994). 16th Canadian Geotechnical Colloquium: Frost heave in soils. Concepts and engineering. Can. Geotech. J. 31, No. 2, 223-245.

Konrad, J. M. \& Duquennoi, C. (1993). A model for water transport and ice lensing in freezing soils. Water Resour. Res. 29, No. 9, $3109-3124$.

Konrad, J. M. \& Morgenstern, N. R. (1980). A mechanistic theory of ice lens formation in fine-grained soils. Can. Geotech. J. 17, No. 4, 473-486.

Mackay, J. R. (1980). The origin of hummocks, western Arctic coast, Canada. Can. J. Earth Sci. 17, No. 11, 996-1006.

Mackay, J. R. (1981). Active layer slope movement in a continuous permafrost environment, Garry Island, Northwest Territories, Canada. Can. J. Earth Sci. 18, No. 11, 1666-1680.

Mackay, J. R. (1983). Downward water-movement into frozen ground, western Arctic coast, Canada. Can. J. Earth Sci. 20, No. $1,120-134$.

Mageau, D. W. \& Morgenstern, N. R. (1980). Observations on moisture migration in frozen soils. Can. Geotech. J. 17, No. 1, $54-60$.

Matsuoka, N. (2001). Solifluction rates, processes and landforms: a global review. Earth Sci. Rev. 55, No. 1, 107-134.

Miller, R. (1978). Frost heaving in non-colloidal soils. Proc. 3rd Int. Conf. on Permafrost, Edmonton, 708-713.

Miller, R. D. (1972). Freezing and heaving of saturated and unsaturated soils. Highway Res. Rec., No. 393, 1-11.

Nakano, Y. (1990). Quasi-steady problems in freezing soils. 1. Analysis on the steady growth of an ice layer. Cold Regions Sci. Technol. 17, 207-226.

Nixon, J. F. D. (1991). Discrete ice lens theory for frost heave in soils. Can. Geotech. J. 28, No. 8, 843-859.

O'Neill, K. \& Miller, R. D. (1985). Exploration of a rigid ice model of frost heave. Water Resour. Res. 21, No. 3, 281296.

Ono, T. (2002). Lateral deformation of freezing clay under triaxial stress condition using laser-measuring device. Cold Regions Sci. Technol. 35, No. 1, 45-54.

Outcalt, S. I., Nelson, F. E. \& Hinkel, K. M. (1990). The zerocurtain effect: heat and mass-transfer across an isothermal region in freezing soil. Water Resour. Res. 26, No. 7, 15091516.

Patterson, D. E. \& Smith, M. W. (1981). The measurement of unfrozen water-content by time domain reflectometry: results from laboratory tests. Can. Geotech. J. 18, No. 1, 131144.

Penner, E. (1986). Aspects of ice lens growth in soils. Cold Regions Sci. Technol. 13, No. 1, 91-100.

Terzaghi, K. (1943). Theoretical soil mechanics. New York: John Wiley \& Sons. 
Thomas, H. R. \& He, Y. (1995). Analysis of coupled heat, moisture and air transfer in a deformable unsaturated soil. Géotechnique 45, No. 4, 677-689.

Thomas, H. R. \& He, Y. (1997). A coupled heat-moisture transfer theory for deformable unsaturated soil and its algorithmic implementation. Int. J. Numer. Methods Engng 40, No. 18 , $3421-3441$.
Tice, A. R., Anderson, D. M. \& Banin, A. (1976). The prediction of unfrozen water contents in frozen soils from liquid limit determinations. CRREL, US Army Corps of Engineers.

Tsytovich, N. A. (1975). The mechanics of frozen ground. Washington, DC: Scripta.

Zienkiewicz, O. C. \& Taylor, R. L. (2000). The finite element method. Vol. 1: The basis. Oxford: Butterworth-Heinemann. 